\title{
Predictors of Low Birth Weight at Lumbini Provincial Hospital, Nepal: A Hospital-Based Unmatched Case Control Study
}

\author{
Saneep Shrestha $\mathbb{D}^{1},{ }^{1}$ Sandeep Shrestha $\mathbb{D}^{2},{ }^{2}$ Upasana Shakya Shrestha, ${ }^{3}$ \\ and Kamala Gyawali ${ }^{4}$ \\ ${ }^{1}$ Department of Community Medicine, Universal College of Medical Sciences, Ranigaun Bhairawaha, Nepal \\ ${ }^{2}$ Department of Pediatrics, Universal College of Medical Sciences, Ranigaun Bhairawaha, Nepal \\ ${ }^{3}$ Adolescent Empowerment Specialist, CARE Nepal, Laxminagar, Butwal, Nepal \\ ${ }^{4}$ Nursing Coordinator, Lumbini Provincial Hospital, Hospital Road, Butwal, Nepal
}

Correspondence should be addressed to Saneep Shrestha; saneep575@gmail.com

Received 27 January 2020; Accepted 4 March 2020; Published 26 March 2020

Academic Editor: Diego A. S. Silva

Copyright (c) 2020 Saneep Shrestha et al. This is an open access article distributed under the Creative Commons Attribution License, which permits unrestricted use, distribution, and reproduction in any medium, provided the original work is properly cited.

\begin{abstract}
Background. Low birth weight (LBW) is defined as the birth weight of live born infants below $2500 \mathrm{~g}$, regardless of gestational age. It is a public health problem caused by factors that are potentially modifiable. The purpose of this study was to determine the socioeconomic, obstetric, and maternal factors associated with LBW in Lumbini Provincial Hospital, Nepal. Methods. The study was conducted using case control study design with $1: 2$ case control ratio. A total of 105 cases and 210 controls were taken in this study. Data were entered on Epi data software version 3.1 and exported to Statistical Package for Social Science (SPSS) software version 25 for analysis. Characteristics of the sample were described using mean and standard deviation. Bivariate analysis was done to assess the association between dependent and independent variables. The ultimate measure of association was odds ratio. Variables found to be associated with bivariate analysis were entered into a multivariable logistic regression model to identify predictors of LBW. Results. The mean age of the participants was 25.98 years with \pm 4.40 standard deviation. Mothers with literate educational background (AOR 0.32, 95\% CI 0.13-0.81), housewife (AOR 2.63, 95\% CI 1.11-6.20), vaginal mode of delivery (AOR $0.45,95 \%$ CI $0.25-0.82$ ), gestational age $<37$ weeks (AOR 2.51, 95\% CI 1.15-5.48), history of LBW (AOR 5.12, 95\% CI 1.93-13.60), and maternal weight $<50$ kilograms (AOR 2.23, 95\% CI 1.23-4.02) were significantly associated with LBW. Conclusion. Educational and occupational status, mode of delivery, gestational age, maternal weight, and history of LBW were found to be independent predictors of LBW. There is need of developing coordination with education sector for increasing educational status of mothers and adolescent girls. Social determinants of health need to be considered while developing interventional programs. Similarly, interventional programs need to be developed considering identified predictors of low birth weight.
\end{abstract}

\section{Background}

The World Health Organization (WHO) defines low birth weight (LBW) as the birth weight of live born infants below $2500 \mathrm{~g}$, regardless of gestational age [1]. Global prevalence of low birth weight is estimated to be $14.6 \%$ with prevalence varying across regions from $7.2 \%$ in developed regions to $17.3 \%$ in Asia and within region from $5.6 \%$ in central Asia to 27.2\% in Southern Asia [2]. Information regarding birth weight is of great importance as it is an indirect indicator of maternal nutrition and predictive indicator of potential neonatal death and malnutrition if the child survives [3]. LBW babies have higher probability of dying within the first month of life or associated with adverse health outcomes like stunted growth [4], delayed motor and social development or learning disabilities [5], lower IQ [6], and high mortality [7]. Also LBW shares higher proportion of global neonatal mortality which is estimated to be around $60-80 \%$ [8].

Risk factors for low birth weight are mainly associated with socioeconomic and maternal factors. Socioeconomic factors associated with low birth weight include place of residence, occupation, educational status, and wealth index 
[9]. Similarly, maternal factors associated with low birth weight include preterm delivery, history of low birth weight, maternal age, height, $\mathrm{Hb}$ level, iron supplementation, and frequency of Ante Natal Care (ANC) visit [9-12].

Previous studies conducted in Nepal have shown that the prevalence of low birth weight ranges from $9.4 \%$ to $21.6 \%$ [13-15]. Furthermore, the UNICEF and WHO estimate prevalence of low birth weight in Nepal to be $21.8 \%$ which is third highest in the world [2]. Despite significant efforts made from the Nepal health sector, prevalence of LBW remains to be high and there has been no change in prevalence of LBW between 2011 and 2016 as per the Nepal Demographic and Health Survey report. Also study conducted on LBW using case control design is limited in country settings of Nepal. Therefore, this study was mainly conducted to identify the socioeconomic, obstetric, and maternal factors associated with low birth weight. This study also aims to provide valuable information for other researchers, health service providers, and policy makers in developing interventional programs for achieving global nutrition third target of $30 \%$ reduction of low birth weight by 2025 [16].

\section{Materials and Methods}

2.1. Study Design and Setting. Institutional-based case control study was conducted at Lumbini Provincial Hospital, located at Butwal, Lumbini zone, Nepal, from June to July 2019. The hospital was established in 1967 and named as Lumbini zonal hospital and later upgraded to Lumbini Provincial Hospital in 2019. Currently, the catchment population of the hospital is four million and serves to thirteen districts of the western part of Nepal.

2.2. Study Population. Postpartum mothers who recently delivered live newborn babies were taken as study population. A case was defined as a mother who delivered a baby weighing less than $2500 \mathrm{~g}$ in Lumbini Provincial Hospital between $1^{\text {st }}$ June and $31^{\text {st }}$ July 2019 . Similarly, control was defined as a mother who delivered a baby weighing at least $2500 \mathrm{~g}$ and not exceeding $4000 \mathrm{~g}$ in the same health facility and time frame. Newborn baby fulfilling the definition of case and control and mothers giving informed consent was included in the study. Similarly, in this study, stillbirths and newborn baby with congenital abnormalities was set as exclusion criteria.

2.3. Sample Size and Sampling Techniques. The sample size was calculated using Open Epi Version 3.01 statistical software for unmatched case control study. Basic parameters assumed for calculating sample size was $95 \%$ confidence level, power of study $80 \%$, ratio of control to case $2: 1$, minimum detectable odds ratio of two, and proportion of control exposed 35\% [17]. The calculated sample size was 100 cases and 200 controls. Additional 5\% sample was taken for adjustment of nonresponse and missing data giving final sample size of 105 cases and 210 controls. Age and sex matching was done during selection of controls. Two controls were selected on the same day when a case was found, and controls were selected randomly for more than two eligible controls.

2.4. Data Collection Tool and Measurement. Data were collected using a structured questionnaire which was prepared after reviewing similar studies conducted in Nepal and other similar country settings. The questionnaire consisted of sociodemographic, socioeconomic, and obstetric information. Obstetric information was collected by reviewing the obstetric records of the participants. One-day training was provided to two hospital staff having bachelor's degree in nursing educational background for data collection procedure. All the filled questionnaires were reviewed and checked for errors by the principal investigator on regular basis.

2.5. Data Processing and Analysis. Data were entered on Epi data software version 3.1 and exported to Statistical Package for Social Science (SPSS) software version 25 for analysis. Characteristics of the sample were described using mean and standard deviation. Bivariate analysis was carried out to assess the association between dependent and independent variables. The ultimate effect measure (measure of association) was odds ratio, and $95 \%$ confidence intervals were used to determine statistical significance. Variables found to be associated with bivariate analysis were entered into the multivariate logistic regression model to identify predictors of LBW.

2.6. Ethical Consideration. Ethical approval was obtained from the Universal College of Medical Science and Teaching Hospital Institutional Review Committee (UCMS/IRC/067/ 19). Permission was also obtained from the Medical Superintendent and Obstetric Department of Lumbini Provincial Hospital to access the participants and their records. The study was explained to participants, and written informed consent with sign or thumb print was obtained for data collection.

\section{Results}

3.1. Sociodemographic Characteristics of Respondents. Table 1 shows the sociodemographic characteristics of mothers who delivered at Lumbini Provincial Hospital between $1^{\text {st }}$ June and $31^{\text {st }}$ July 2019. A total of 315 mothers (105 cases and 210 controls) participated in the study. The mean age of mothers was found to be 25.98 years with \pm 4.40 standard deviation. Among study participants, 227 (72.1\%) mothers were of the age group of 20-30 years, 169 (53.7\%) were of upper caste, 281 (89.2\%) were literate, 188 (59.7\%) were living in nuclear family, and 250 (79.4\%) were housewives.

3.2. Maternal and Obstetric Characteristics of Respondents. Table 2 shows the maternal and obstetric characteristics of mothers. Mode of child delivery was vaginal (198 (62.9\%). Parity of mothers was almost equal with 161 (51.1\%) primiparity. 
TABle 1: Sociodemographic characteristics of study participants, Lumbini Provincial Hospital, 2019.

\begin{tabular}{|c|c|c|c|}
\hline Variables & Category & Frequency & Percentage \\
\hline \multirow{3}{*}{ Age group of respondent } & $<20$ & 18 & 5.7 \\
\hline & $20-30$ & 227 & 72.1 \\
\hline & $>30$ & 70 & 22.2 \\
\hline \multirow{4}{*}{ Ethnicity of respondent } & Dalit & 36 & 11.4 \\
\hline & Janjati & 79 & 25.1 \\
\hline & Religious minorities & 31 & 9.8 \\
\hline & Upper caste & 169 & 53.7 \\
\hline \multirow{2}{*}{ Educational status of respondent } & Literate & 281 & 89.2 \\
\hline & Illiterate & 34 & 10.8 \\
\hline \multirow{3}{*}{ Occupation of respondent } & Labor/wage worker & 17 & 5.4 \\
\hline & Unemployed/wousewife & 250 & 79.4 \\
\hline & Employed & 48 & 15.2 \\
\hline \multirow{2}{*}{ Family type of respondent } & Nuclear & 188 & 59.7 \\
\hline & Joint & 127 & 40.3 \\
\hline
\end{tabular}

TABle 2: Maternal and obstetric characteristics of study participants, Lumbini Provincial Hospital, 2019.

\begin{tabular}{|c|c|c|c|}
\hline Variables & Category & Frequency & Percentage \\
\hline \multirow{2}{*}{ Mode of delivery } & $\begin{array}{l}\text { Cesarean } \\
\text { section }\end{array}$ & 198 & 62.9 \\
\hline & Vaginal & 117 & 37.1 \\
\hline \multirow{2}{*}{ Gestational age } & $<37$ weeks & 48 & 15.2 \\
\hline & $\geq 37$ weeks & 267 & 84.8 \\
\hline \multirow{2}{*}{ Parity } & Primiparity & 161 & 51.1 \\
\hline & Multiparity & 154 & 48.9 \\
\hline \multirow{2}{*}{ History of abortion } & Yes & 28 & 8.9 \\
\hline & No & 287 & 91.1 \\
\hline \multirow{2}{*}{$\begin{array}{l}\text { History of low birth } \\
\text { weight }\end{array}$} & Yes & 24 & 7.6 \\
\hline & No & 291 & 92.4 \\
\hline \multirow{2}{*}{ Maternal weight } & $<50$ kilograms & 75 & 23.8 \\
\hline & $\geq 50$ kilograms & 240 & 76.2 \\
\hline \multirow{2}{*}{ ANC visit } & $\geq 4$ visit & 251 & 79.7 \\
\hline & $<4$ visit & 64 & 20.3 \\
\hline \multirow{2}{*}{ Hb level } & $<11 \mathrm{~g} / \mathrm{dl}$ & 243 & 77.1 \\
\hline & $\geq 11 \mathrm{~g} / \mathrm{dl}$ & 72 & 22.9 \\
\hline \multirow{2}{*}{ Rest during day time } & $\leq 2$ hours & 276 & 87.6 \\
\hline & $>2$ hours & 39 & 12.4 \\
\hline \multirow{2}{*}{ Rest during night time } & $<8$ hours & 253 & 80.3 \\
\hline & $\geq 8$ hours & 62 & 19.7 \\
\hline
\end{tabular}

Proportion of mothers with a history of abortion and low birth weight was 28 (8.9\%) and 24 (7.6\%), respectively. Preterm delivery was prevalent in $48(15.2 \%)$ mothers. Proportion of mothers with ANC visit of 4 or more was 251 (79.7\%). Mean weight and hemoglobin level of mothers were found to be $54.53 \mathrm{~kg}$ and $10.20 \mathrm{~g} / \mathrm{dl}$ with a standard deviation of \pm 6.69 and \pm 1.19 , respectively. Proportion of mothers with weight more than or equal to $50 \mathrm{~kg}$ was 240 $(76.2 \%)$ and hemoglobin level more than $11 \mathrm{~g} / \mathrm{dl}$ was 72 (22.9\%). Majority of women were not having adequate amount of rest and sleep during day and night time. Proportion of women with rest time of more than 2 hours in day time and $\geq 8$ hours in night time was 39 (12.4\%) and $62(19.7 \%)$, respectively.
3.3. Sociodemographic Predictors of $L B W$. Table 3 shows sociodemographic predictors of low birth weight. Results from bivariate analysis revealed mother's age, ethnicity, educational status, occupation, and wealth index as significant variables to be associated with low birth weight which was further entered into the multivariate regression analysis model for confounding adjustment. Results from the multivariate regression analysis model identified educational status and occupation of mothers as sociodemographic predictors of low birth weight. Literate mothers were found to have protective effect for LBW (AOR 0.32, 0.13-0.81). Similarly, the odds of having LBW infants were high among mothers whose occupation was labor or wage worker (AOR 5.21, CI 1.13-23.88) and were unemployed (AOR 2.63, CI $1.11-6.20)$.

3.4. Maternal and Obstetric Predictors of $L B W$. Table 4 shows maternal and obstetric determinants of LBW. Factors associated with LBW, resulting from bivariate analysis, were entered into the multivariate regression analysis model which identified mode of delivery, gestational age, history of LBW, and maternal weight as maternal and obstetric predictors of LBW. Odds of LBW increased significantly with decrease in gestational age (AOR 2.51, CI 1.15-5.48) and maternal weight (AOR 2.23, CI 1.23-4.02). Similarly, odds of having LBW with cesarean delivery were twice (AOR 2.19, CI 1.21-3.97) and high among mothers with a previous history of LBW (AOR 5.12, CI 1.93-13.60).

\section{Discussion}

This study aimed at determining the sociodemographic, maternal, and obstetric predictors of low birth weight. Literate mothers were $68 \%$ less likely to have low weight babies compared to their illiterate counterpart. This finding is consistent with other studies where literate mothers were found to have a protective effect against LBW [18-21]. Mothers involved in labor work were five times and mothers who were unemployed or housewives were two times more likely to deliver LBW baby than the employed counterpart. 
TABLE 3: Sociodemographic predictors of LBW.

\begin{tabular}{|c|c|c|c|c|c|c|}
\hline Variables & Cases $(\%)(n=105)$ & Control $(n=210)$ & COR & $95 \% \mathrm{CI}$ & AOR & $95 \% \mathrm{CI}$ \\
\hline \multicolumn{7}{|l|}{ Mothers age group } \\
\hline$<20$ & $11(10.5)$ & $7(3.3)$ & 3.45 & $1.28-9.27^{*}$ & 2.71 & $0.93-7.94$ \\
\hline $20-30$ & $71(67.6)$ & $156(74.3)$ & 1 & & 1 & \\
\hline$>30$ & $23(21.9)$ & $47(22.4)$ & 1.07 & $0.60-1.90$ & 1.18 & $0.63-2.21$ \\
\hline \multicolumn{7}{|l|}{ Respondent ethnicity } \\
\hline Dalit & $19(18.1)$ & $17(8.1)$ & 2.51 & $1.21-5.22^{*}$ & 1.77 & $0.79-3.92$ \\
\hline Janjati & $21(20.0)$ & $58(27.6)$ & 0.81 & $0.44-1.47$ & 0.62 & $0.32-1.19$ \\
\hline Religious minorities & $13(12.4)$ & $18(8.6)$ & 1.62 & $0.74-3.56$ & 0.44 & $0.15-1.30$ \\
\hline Upper caste & $52(49.5)$ & $117(55.7)$ & 1 & & 1 & \\
\hline \multicolumn{7}{|c|}{ Respondent educational status } \\
\hline Literate & $83(79)$ & $198(94.3)$ & 0.22 & $0.10-0.48^{*}$ & 0.32 & $0.13-0.81^{* *}$ \\
\hline Illiterate & $22(21)$ & $12(5.7)$ & 1 & & 1 & \\
\hline \multicolumn{7}{|l|}{ Occupation of respondent } \\
\hline Labor/wage worker & $11(10.5)$ & $6(2.9)$ & 9.16 & $2.62-32.03^{*}$ & 5.21 & $1.13-23.88^{* *}$ \\
\hline Unemployed/housewife & $86(81.9)$ & $164(78.1)$ & 2.62 & $1.17-5.85$ & 2.63 & $1.11-6.20$ \\
\hline Employed & $8(7.6)$ & $40(19)$ & 1 & & 1 & \\
\hline \multicolumn{7}{|l|}{ Family type of respondent } \\
\hline Nuclear & $70(66.7)$ & $118(56.2)$ & 1.55 & $0.95-2.54$ & & \\
\hline Joint & $35(33.3)$ & $92(43.8)$ & 1 & & & \\
\hline \multicolumn{7}{|l|}{ Wealth index } \\
\hline Poorest & $32(30.5)$ & $31(14.8)$ & 2.58 & $1.23-5.39^{*}$ & 1.71 & $0.73-4.03$ \\
\hline Poorer & $18(17.1)$ & $44(21.0)$ & 1.02 & $0.47-2.21$ & 0.97 & $0.42-2.22$ \\
\hline Middle & $21(20.0)$ & $43(20.5)$ & 1.22 & $0.57-2.59$ & 1.19 & $0.54-2.62$ \\
\hline Richer & $16(15.2)$ & $47(22.4)$ & 0.851 & $0.38-1.87$ & 0.91 & $0.40-2.07$ \\
\hline Richest & $18(17.1)$ & $45(21.4)$ & 1 & & & \\
\hline
\end{tabular}

*Variables entered to multivariate regression model, ${ }^{* *}$ Statistically significant at $\mathrm{p}$-value $<0.05$, adjusted model.

TABLE 4: Maternal and obstetric predictors of LBW.

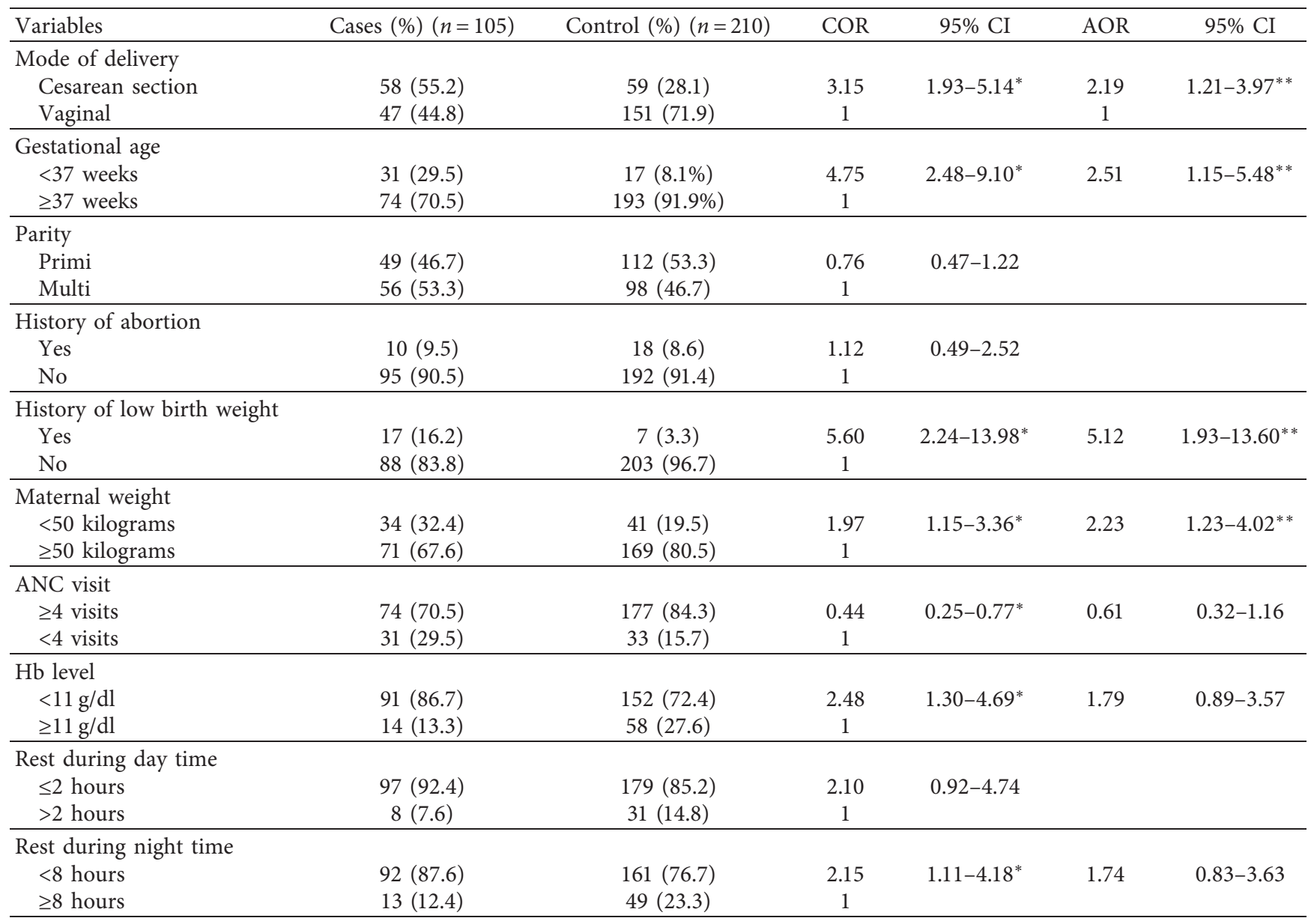

${ }^{*}$ Variables entered to multivariate regression model, ${ }^{* *}$ Statistically significant at $\mathrm{p}$-value $<0.05$, adjusted model. 
This finding aligns with the study conducted in Lithuania, Vientiane, and Nepal [22-24] which revealed that mother's employment status is significantly associated with LBW. The role of education and employment on infant birth weight might be due to various interactions among social determinants of health. Mothers with low educational attainment are prone to low health seeking behavior and more likely to be unemployed which further can lead to deprivation of nutritious food, good housing condition, and wealth which are found to be independent risk factors of LBW [19, 25-27].

The odds of delivering LBW baby among mothers with a previous history of LBW were five times higher than that of mothers with no previous history of LBW. This finding is similar to the study conducted in Ethiopia [10]. Similarly, odds of delivering LBW baby were twice among mothers with preterm delivery compared to mothers who delivered at term pregnancy. This finding parallels with the previous randomized control trial study conducted in Kenya [28], cohort study conducted in Ethiopia [29], and case control study conducted in Ghana [30], Ethiopia [11,31], and Nepal [32]. In this study, significant association was observed between mode of delivery and LBW with odds of LBW among cesarean delivery being twice compared to vaginal delivery. The study findings align with the previous studies conducted in Kenya [28], Spain [33], Brazil [34], and Iran [35]. The observed association should be understood cautiously as maternal conditions of having twins, with a gestational age of less than 37 weeks, are more prone to cesarean delivery and are found to be contributing factors for LBW [10, 34]. However, no significant association was observed between mode of delivery and LBW in a study conducted in Nepal [13]. In this study, low maternal weight was found to be an independent risk factor for LBW which is supported by findings of previous study conducted in India $[36,37]$ and Ethiopia [38] using case control and crosssectional study design, respectively.

Regular ANC during pregnancy is beneficial for both the pregnant mother and developing baby as obstetric complications can be identified during ANC and managed timely [18]. Studies conducted in Malawi and Uganda [39], Ethiopia [29], and Bangladesh [40] have identified an inadequate number of ANC visits to be associated with higher odds of LBW. However, no significant association was observed between the number of ANC visits and LBW in our study.

Despite extensive endeavors made in the study, it could not avert three basic limitations. First, the study findings cannot be generalized to mothers attending private hospitals or clinics, mothers delivering baby at home, and mothers living in areas other than the study area. Second, being a case control study, the study participants may have been subjected to recall bias. The third limitation of this study was we could not assess the relationship between weight gain during pregnancy and risk of LBW as data related to maternal weight during regular intervals of pregnancy was not available in our study. However, we took maternal weight during first trimester as a proxy for prepregnancy maternal weight which could have been a better measure for assessing LBW [41].

\section{Conclusion}

Educational and occupational status, mode of delivery, gestational age, maternal weight, and history of LBW were found to be independent predictors of LBW. There is need of developing coordination with education sector for increasing educational status of mothers and adolescent girls. Social determinants of health need to be considered while developing interventional programs. Similarly, interventional programs need to be developed considering identified predictors of low birth weight.

\section{Abbreviations \\ ANC: Antenatal care \\ AOR: Adjusted odds ratio \\ CI: Confidence interval \\ COR: Crude odds ratio \\ LBW: Low birth weight \\ WHO: World Health Organization.}

\section{Data Availability}

The data used to support the findings of this study are available from the corresponding author upon request.

\section{Conflicts of Interest}

The authors declare that they have no conflicts of interest.

\section{Acknowledgments}

The authors would like to thank all the participants of the study who gave us their consent to take part on the study and staff members of the hospital who helped in data collection. The authors would also like to thank the Universal College of Medical Science and Teaching Hospital for granting approval for the research work.

\section{References}

[1] World Health Organization, International Statistical Classification of Diseases and Related Health Problems, World Health Organization, Geneva, Switzerland, 2010, https:// www.who.int/classifications/icd/ICD10Volume2_en_2010. pdf.

[2] United Nations Children's Fund, World Health Organization, UNICEF-WHO Low Birthweight Estimates: Levels and Trends 2000-2015, World Health Organization, Geneva, Switzerland, 2019, https://apps.who.int/iris/bitstream/handle/10665/ 324783/WHO-NMH-NHD-19.21-eng.pdf?ua=1.

[3] Ministry of Health-MOH/Nepal, ICF. Nepal Demographic and Health Survey 2016, Ministry of Health-MOH/Nepal, Kathmandu, Nepal, 2017.

[4] R. J. Scharf, A. Stroustrup, M. R. Conaway, and M. D. DeBoer, "Growth and development in children born very low birthweight," Archives of Disease in Childhood-Fetal and Neonatal Edition, vol. 101, no. 5, pp. F433-F438, 2016.

[5] Centers for Disease Control and Prevention, Reproductive And Birth Outcomes, Centers for Disease Control and Prevention, Atlanta, GA, USA, 2016, https://ephtracking.cdc.gov/ showRbLBWGrowthRetardationEnv.action. 
[6] H. Gu, L. Wang, L. Liu et al., "A gradient relationship between low birth weight and IQ: a meta-analysis," Scientific Reports, vol. 7, no. 1, p. 18035, 2017.

[7] M. O'Leary, K. Edmond, S. Floyd, S. Newton, G. Thomas, and S. L. Thomas, "A cohort study of low birth weight and health outcomes in the first year of life, Ghana," Bulletin of the World Health Organization, vol. 95, no. 8, p. 574, 2017.

[8] World Health Organization, Care of the Preterm and LowBirth-Weight Newborn 2018, World Health Organization, Geneva, Switzerlan, 2018, https://www.who.int/maternal_ child_adolescent/newborns/prematurity/en/.

[9] R. A. Mahumud, M. Sultana, and A. R. Sarker, "Distribution and determinants of low birth weight in developing countries," Journal of Preventive Medicine and Public Health, vol. 50, no. 1, pp. 18-28, 2017.

[10] A. Talie, M. Taddele, and M. Alemayehu, "Magnitude of low birth weight and associated factors among newborns delivered in dangla primary hospital, amhara regional state, northwest Ethiopia," Journal of Pregnancy, vol. 2019, p. 6, 2019.

[11] G. Asmare, N. Berhan, M. Berhanu, and A. Alebel, "Determinants of low birth weight among neonates born in Amhara Regional State Referral Hospitals of Ethiopia: unmatched case control study," BMC Research Notes, vol. 11, no. 1, p. 447, 2018.

[12] Y. Gebregzabiherher, A. Haftu, S. Weldemariam, and H. Gebrehiwet, "The prevalence and risk factors for low birth weight among term newborns in adwa general hospital, northern Ethiopia," Obstetrics and Gynecology International, vol. 2017, Article ID 2149156, 7 pages, 2017.

[13] R. Prajapati, S. Shrestha, and N. Bhandari, "Prevalence and associated factors of low birth weight among newborns in a tertiary level hospital in Nepal," Kathmandu University Medical Journal, vol. 16, no. 61, pp. 49-52, 2018.

[14] U. Singh, A. Ueranantasun, and M. Kuning, "Factors associated with low birth weight in Nepal using multiple imputation," BMC Pregnancy Childbirth, vol. 17, no. 1, p. 67, 2017.

[15] K. P. Kandel and S. Kafle, "Risk factors associated with low birth weight among deliveries at bharatpur hospital," Journal of Nepal Health Research Council, vol. 15, no. 2, pp. 169-173, 2017.

[16] United Nations Children's Fund, World Health Organization, Global Nutrition Monitoring Framework Operational Guidance for Tracking Progress in Meeting Targets for 2025, World Health Organization, Geneva, Switzerland, 2017, https://apps. who.int/iris/bitstream/handle/10665/259904/9789241513609eng.pdf;jsessionid=5B68A51D12CBC12C181123ADF83125E2? sequence $=1$.

[17] A. G. Dean, K. M. Sullivan, and M. M. Soe, "Openepi: open source epidemiologic statistics for public health," 2013, https://www.openepi.com/Menu/OE_Menu.htm.

[18] S. Mohammed, I. Bonsing, I. Yakubu, and W. P. Wondong, "Maternal obstetric and socio-demographic determinants of low birth weight: a retrospective cross-sectional study in Ghana," Reproductive Health, vol. 16, no. 1, p. 70, 2019.

[19] R. Das Gupta, K. Swasey, V. Burrowes, M. R. Hashan, and G. M. Al Kibria, "Factors associated with low birth weight in Afghanistan: a cross-sectional analysis of the demographic and health survey 2015," BMJ Open, vol. 9, no. 5, Article ID e025715, 2019.

[20] R. K. Bhaskar, K. K. Deo, U. Neupane et al., "A case control study on risk factors associated with low birth weight babies in eastern Nepal," International Journal of Pediatrics, vol. 2015, Article ID 807373, 7 pages, 2015.
[21] D. K. Yadav, U. Chaudhary, and N. Shrestha, "Risk factors associated with low birth weight," Journal of Nepal Health Research Council, vol. 9, no. 9, pp. 159-164, 2011.

[22] J. Dickute, Z. Padaiga, V. Grabauskas, R. J. Nadisauskiene, V. Basys, and A. Gaizauskiene, "Maternal socio-economic factors and the risk of low birth weight in Lithuania," Medicina (Kaunas, Lithuania), vol. 40, no. 5, pp. 475-482, 2004.

[23] L. Viengsakhone, Y. Yoshida, M. Harun-Or-Rashid, and J. Sakamoto, "Factors affecting low birth weight at four central hospitals in vientiane, Lao PDR," Nagoya Journal of Medical Science, vol. 72, no. 1-2, pp. 51-58, 2010.

[24] D. Acharya, J. K. Singh, R. Kadel, S. J. Yoo, J. H. Park, and K. Lee, "Maternal factors and utilization of the antenatal care services during pregnancy associated with low birth weight in rural Nepal: analyses of the antenatal care and birth weight records of the MATRI-SUMAN trial," International Journal of Environmental Research and Public Health, vol. 15, no. 11, 2018.

[25] N. Khan, A. Mozumdar, and S. Kaur, "Determinants of low birth weight in India: an investigation from the national family health survey," American Journal of Human Biology: The Official Journal of the Human Biology Council, 2019.

[26] Z. Abera, D. Ejara, and S. Gebremedhin, "Nutritional and non-nutritional factors associated with low birth weight in sawula town, gamo gofa zone, southern Ethiopia," BMC Research Notes, vol. 12, no. 1, p. 540, 2019.

[27] M. V. Vettore, S. G. N. d. Gama, G. d. A. Lamarca, A. O. C. Schilithz, and M. d. C. Leal, "Housing conditions as a social determinant of low birthweight and preterm low birthweight," Revista de Saúde Pública, vol. 44, no. 6, pp. 1021-1031, 2010.

[28] C. K. Nyamasege, E. W. Kimani-Murage, M. Wanjohi et al., "Determinants of low birth weight in the context of maternal nutrition education in urban informal settlements, Kenya," Journal of Developmental Origins of Health and Disease, vol. 10, no. 2, pp. 237-245, 2019.

[29] M. Desta, M. Tadese, B. Kassie, and M. Gedefaw, "Determinants and adverse perinatal outcomes of low birth weight newborns delivered in Hawassa University Comprehensive Specialized Hospital, Ethiopia: a cohort study," BMC Research Notes, vol. 12, no. 1, p. 118, 2019.

[30] Z. Adam, D. K. Ameme, P. Nortey, E. A. Afari, and E. Kenu, "Determinants of low birth weight in neonates born in three hospitals in Brong Ahafo region, Ghana, 2016- an unmatched case-control study," BMC Pregnancy Childbirth, vol. 19, no. 1, p. 174, 2019.

[31] L. D. Hailu and D. L. Kebede, "Determinants of low birth weight among deliveries at a referral hospital in northern Ethiopia," BioMed Research International, vol. 2018, Article ID 8169615, 8 pages, 2018.

[32] S. R. Sharma, S. Giri, U. Timalsina et al., "Low birth weight at term and its determinants in a tertiary hospital of Nepal: a case-control study," PLoS One, vol. 10, no. 4, Article ID e0123962, 2015.

[33] P. Hidalgo-Lopezosa, A. Jiménez-Ruz, J. M. Carmona-Torres, M. Hidalgo-Maestre, M. A. Rodríguez-Borrego, and P. J. López-Soto, "Sociodemographic factors associated with preterm birth and low birth weight: a cross-sectional study," Women and Birth, vol. 32, no. 6, pp. e538-e543, 2019.

[34] A. I. M. Moreira, P. R. M. Sousa, and F. Sarno, "Low birth weight and its associated factors," Einstein (Sao Paulo).vol. 16, no. 4, Article ID eAO4251, 2018.

[35] M. Momeni, M. Danaei, A. J. Kermani et al., "Prevalence and risk factors of low birth weight in the southeast of Iran," 
International Journal of Preventive Medicine, vol. 8, no. 8, p. 12, 2017.

[36] S. S. Mumbare, G. Maindarkar, R. Darade, S. Yenge, M. K. Tolani, and K. Patole, "Maternal risk factors associated with term low birth weight neonates: a matched-pair case control study," Indian Pediatrics, vol. 49, no. 1, pp. 25-28, 2012.

[37] S. Ganesh Kumar, H. N. Harsha Kumar, S. Jayaram, and M. S. Kotian, "Determinants of low birth weight: a case control study in a district hospital in Karnataka," The Indian Journal of Pediatrics, vol. 77, no. 1, pp. 87-89, 2010.

[38] M. Gebremedhin, F. Ambaw, E. Admassu, and H. Berhane, "Maternal associated factors of low birth weight: a hospital based cross-sectional mixed study in Tigray, Northern Ethiopia," BMC Pregnancy Childbirth, vol. 15, p. 222, 2015.

[39] Z. He, G. Bishwajit, S. Yaya, Z. Cheng, D. Zou, and Y. Zhou, "Prevalence of low birth weight and its association with maternal body weight status in selected countries in Africa: a cross-sectional study," BMJ Open, vol. 8, no. 8, Article ID e020410, 2018.

[40] S. Khatun and M. Rahman, "Socio-economic determinants of low birth weight in Bangladesh: a multivariate approach," Bangladesh Medical Research Council Bulletin, vol. 34, no. 34, pp. 81-86, 2008.

[41] S. Nahar, C. G. N. Mascie-Taylor, and H. A. Begum, "Maternal anthropometry as a predictor of birth weight," Public Health Nutrition, vol. 10, no. 9, pp. 965-970, 2007. 